\title{
Computational analysis of temperature effect in composite bolted joints for aeronautical applications
}

\author{
Carlos Santiuste', Enrique Barbero' and \\ María Henar Miguélez ${ }^{2}$
}

\begin{abstract}
This study focuses on the analysis of influence of temperature and bolt torque on aeronautical joint behavior. A single-lap joint, according to ASTM D596I, with a titanium bolt and composite plates was considered. A numerical model based on FEM was developed to evaluate the stress in both bolt and composite plates. Load-displacement curves, stress fields, and induced damage showed, significantly, the influence of temperature combined with torque level on the joint. It was found that in the plate, both maximum and minimum levels of torque considered produced damage above critical threshold. This fact should be accounted for, during the design process of the joint.
\end{abstract}

\section{Keywords}

Aeronautical structures, finite element modeling, composite joint, thermo-mechanical load

\section{Introduction}

Composite structures are used extensively in aircraft structures because of the combination of excellent mechanical properties and lightness. Mechanical joining is the most important method of assembling structural elements in the aerospace industry, due to its facility to assemble, disassemble and repair, and its tolerance to environmental effects.

Bolted joints for high responsibility applications on composite structures should be carefully designed. The enhanced stress intensity factor at the surrounding of the hole and the weakness of the composite, make the designing and assembly process more critical in the case of composite joints than in those based on metallic components. Structural safety should be ensured; thus the study of bolted joints in structural composite components has received considerable attention in both scientific literature and aeronautical standards. ${ }^{1} 7$ The joint performance depends on different parameters, mainly: joint geometry, laminate and bolt materials, laminate layup, clearance, friction between different elements of the joint, temperature, load path, and bolt torque.
The procedure for designing composite joints is predominately based on experimental data and the analytical models are largely empirical in nature. ${ }^{7}$ The number of influencing parameters requires powerful tools for joint analysis, such as finite element modeling. Several authors developed studies of composite joints based on two-dimensional models. ${ }^{8,9}$ However, in single-lap joints, the significant variation of through thickness stress in the plate induced three-dimensional stress state in the bolt. This fact has motivated the development of three dimensional models of the

\footnotetext{
'Department of Continuum Mechanics and Structural Analysis, University Carlos III of Madrid, Spain.

${ }^{2}$ Department of Mechanical Engineering, University Carlos III of Madrid, Spain.

Corresponding author:

Carlos Santiuste, Department of Continuum Mechanics and Structural Analysis, University Carlos III of Madrid, Avda. de la Universidad 30, 289I I Leganés, Madrid, Spain Email: csantius@ing.uc3m.es
} 
joint; ${ }^{10}$ however, in some works, the influence of stacking sequence of the laminate was not accounted. , $^{11}$

Aeronautical joints are manufactured under standard values of fastener torque. The level of torque applied to the bolt directly influences the stress fields in both the bolt and the composite plates. In consequence, the maximum value of torque is limited by standards; see for example Thomas and Zhao. ${ }^{7}$ However, low levels of torque could also influence the performance of the joint in a negative way. As was demonstrated in Thoppul et al. ${ }^{2}$ for carbon/epoxy laminates, the bearing strength grow when the clamping pressure is increased.

During its service life, aeronautical structures are subjected to extreme changes in temperature, from $50^{\circ} \mathrm{C}$ and above, to below $-50^{\circ} \mathrm{C}$. Some composite parts adjacent to hot source are exposed to relatively high temperature; by contrast, the structure is subjected to low temperature during the flight. Mechanical properties of polymer composite could be influenced by low and high temperatures as was demonstrated by Sánchez-Sáez et al. ${ }^{12,13}$ Moreover, the joint behavior could be modified even if the composite properties are assumed to remain constant, due to the different coefficients of thermal expansion exhibited by metallic and composite components. The role of temperature on the behavior of structural joints has been poorly analyzed in the scientific literature. Most studies developed an experimental approach. ${ }^{14}{ }^{16}$ Hirano et al. ${ }^{14}$ carried out an experimental study of pinned joint at three temperatures. They analyzed the damage as a function of the load applied. A specimen with a semicircular hole loaded with a pin was used in the tests; therefore no complete joint was tested. Turvey and Wang ${ }^{15}$ analyzed the ultimate load capacity of single-bolt tension joint in pultruded glassreinforced plastic plates. They studied the time necessary to ensure uniform field of temperature. Song et al. ${ }^{16}$ studied experimentally the bearing strength of riveted lap joint of a carbon/epoxy composite after thermal exposure. Scarponi et al. ${ }^{9}$ analyzed the influence of temperature and lateral pressure on strength of a double lap pin loaded joint. They considered four different lateral pressures and five temperatures (from $-150^{\circ} \mathrm{C}$ to $+80^{\circ} \mathrm{C}$ ). A simple bidimensional numerical model was used to estimate the strength of the joint at $-55^{\circ} \mathrm{C}$ and $+80^{\circ} \mathrm{C}$ and four lateral pressures. They found that the failure load increased with the rise of the lateral pressure and with the temperature decrease.

In spite of these works focused on the influence of temperature on composite joints, there is a lack of knowledge about the interaction between the torque preload and the thermal expansion and its influence in the strength of the joint. Main objective of this article is the computational analysis of the influence of combined torque and thermal loading on the behavior of composite bolted joints. The stresses in both laminate and bolt were evaluated, analyzing the induced damage in the composite as a consequence of the interaction between torque and thermal load. A single-lap composite joint according to ASTM D5961 ${ }^{17}$ was selected. A numerical model based on a finite element approach was developed reproducing a typical aeronautical bolted joint between composite plates and titanium bolt.

\section{Numerical model}

\section{Model description}

A numerical model based on finite element method (FEM) reproducing a single bolted joint according to the ASTM 5961 standard, ${ }^{17}$ was developed using the code ABAQUS/Standard. The joint is illustrated in Figure 1, showing bolt, washer, and composite plate geometry. The model was symmetric with respect to the 1-3 plane; thus, only half geometry was modeled and symmetry conditions were specified on the 1-3 plane.

Composite plate. Each composite plate, carbon/epoxy laminate (AS4/3501-6), was modeled as a quasi-isotropic stacking sequence $[ \pm 45 / 0 / 90]_{2 S}$, with total thickness equal to $3.2 \mathrm{~mm}$ and width in direction 2 equal to $36 \mathrm{~mm}$. Composite mechanical behavior was modeled as linear elastic with the anisotropic mechanical properties summarized in Table 1; thermal properties of the composite material are also included. The properties of the AS4/3501-6 composite are well known and can be found in Song et al. ${ }^{18}$

Each ply (0.2 $\mathrm{mm}$ thickness), defined as an anisotropic material, consisted of a single layer of eightnode cubic elements, with reduced integration (C3D8R in ABAQUS ${ }^{19}$ notation). The use of different elements in each ply improved the accuracy for the calculation of through thickness stresses. A high mesh density was used in the hole vicinity (element size around $0.2 \mathrm{~mm}$ ), due to the high strain gradients existing in this zone. Mesh density was stated after successive space discretizations, in order to obtain low mesh sensitivity and time efficiency in the calculation. The process was stopped when no significant changes in numerical results were observed with mesh refinement. The final number of elements used in the model was around 44,300.

Bolt and washer. The joining was developed with a bolt (titanium alloy $\mathrm{Ti}-6 \mathrm{Al}-6 \mathrm{~V}-2 \mathrm{Sn}$, diameter equal to $5.94 \mathrm{~mm}$ ). The washers (see dimensions in Figure 1) were based on the same material. The bolt-hole clearance stated in the joint was equal to $0.06 \mathrm{~mm}$, this value lying within current aerospace standard. ${ }^{5}$ Titanium bolt and washers were modeled according to isotropic linear 


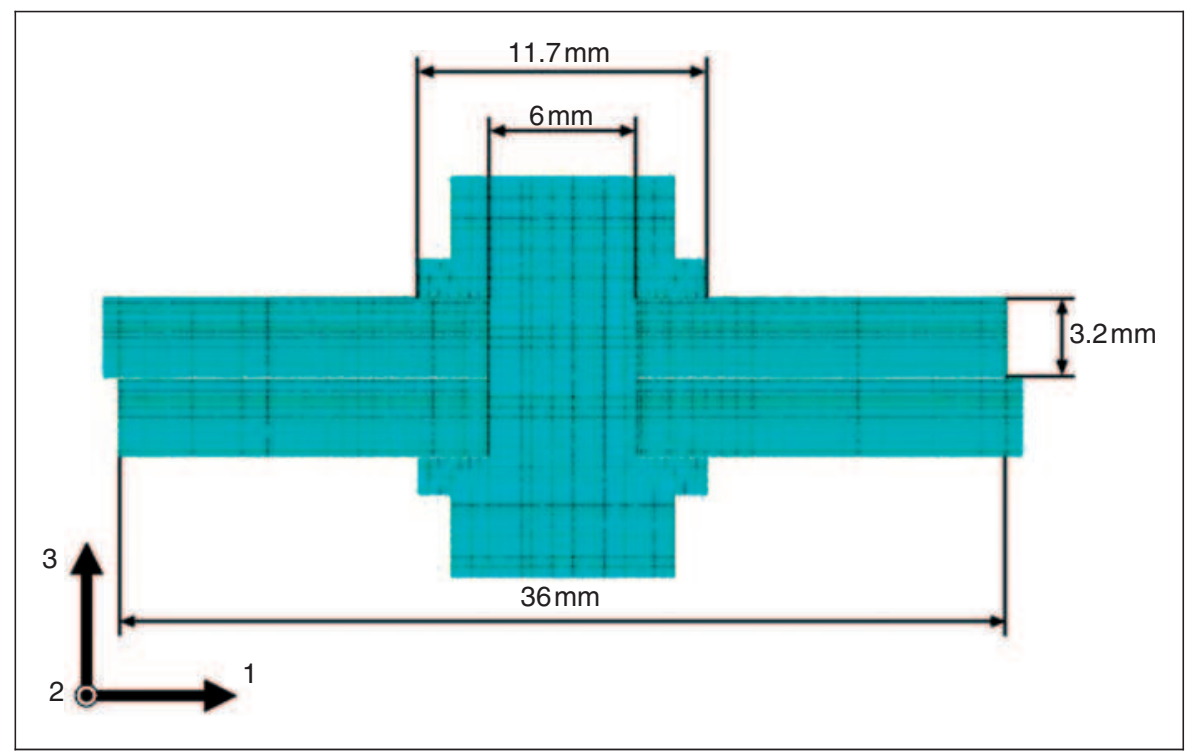

Figure I. Model description showing dimensions, reference system, and mesh.

Table I. AS4/350I 6 properties: mechanical and thermal ${ }^{18}$

Longitudinal modulus, $E_{1}(\mathrm{GPa})$

Transverse modulus, $E_{2}(\mathrm{GPa})$

In plane shear modulus, $G_{12}(\mathrm{GPa})$

Major in plane Poisson ratio, $v_{12}$

Through thickness Poisson ratio, $v_{23}$

Longitudinal tensile strength, $X^{\top}(\mathrm{MPa})$

Longitudinal compressive strength, $X^{\mathrm{C}}(\mathrm{MPa})$

Transverse tensile strength, $Y^{\top}(\mathrm{MPa})$

Transverse compressive strength, $Y^{C}(\mathrm{MPa})$

In plane shear strength, $S^{12}(\mathrm{MPa})$

Longitudinal thermal coefficient, $\alpha_{1}\left(10^{-6} /{ }^{\circ} \mathrm{C}\right)$

Transverse thermal coefficient, $\alpha_{2}\left(10^{-6} /{ }^{\circ} \mathrm{C}\right)$

elastic behavior, with the mechanical and thermal properties shown in Table 2.

Contact. Components interaction was modeled using surface-based contact available in ABAQUS/ Standard. The linear penalty method is used by default for the finite-sliding, surface-to-surface contact formulation. 19

Friction between composite plates and metallic components and also between composite plates was considered. The effect of pressure on friction coefficient was neglected, and constant values of friction coefficient were implemented. At the inner surfaces, friction between metallic parts (bolt and washer) and composite plates was equal to 0.05 , assuming that there was lubrication at these surfaces. Friction coefficient between composite plates was 0.65 . These values were stated

4

Table 2. Titanium alloy $\mathrm{Ti}-6 \mathrm{Al}-6 \mathrm{~V}-2 \mathrm{Sn}$ properties: mechanical and thermal

\begin{tabular}{ll}
\hline Young modulus, $E(\mathrm{GPa})$ & 110 \\
Poisson ratio, $v$ & 0.29 \\
Longitudinal thermal coefficient, $\alpha\left(10^{-6} /{ }^{\circ} \mathrm{C}\right)$ & $8.4 \mathrm{I}$ \\
\hline
\end{tabular}

\section{Loading path}

Fastener torque is limited in aeronautical standards in order to avoid excessive stresses in both the bolt and laminate. In this study, the influence of fastener torque was analyzed, defining four levels of torque: finger tight, nominal torque proposed in the standard ASTM 5961, ${ }^{17}$ and two other values, 30\% below, and $30 \%$ above the nominal value. The effect of torque was introduced using the pretension bolt load option available in ABAQUS/Standard. The equivalence between pretension load and torque was deduced from the work of Chen et al. ${ }^{21}$ The values of pretension in the bolt corresponding to the four levels of torque are shown in Table 3.

Four levels of temperature were implemented, covering the temperature range from typical levels reached during flying operation $\left(-50^{\circ} \mathrm{C}\right)$ to elevated temperature in the zones close to heat sources. High temperature equal to $90^{\circ} \mathrm{C}$ was imposed as an upper limit of temperature that could be reached in areas surrounding heat sources in the aircraft. Two other intermediate 
Table 3. Bolt pretension load

\begin{tabular}{lllll}
\hline Torque levels & Finger tight & $70 \%$ of nominal torque & Nominal torque (ASTM 596I) & I30\% of nominal torque \\
\hline Bolt preload $(\mathrm{N})$ & 450 & 1500 & 2250 & 3000 \\
\hline
\end{tabular}

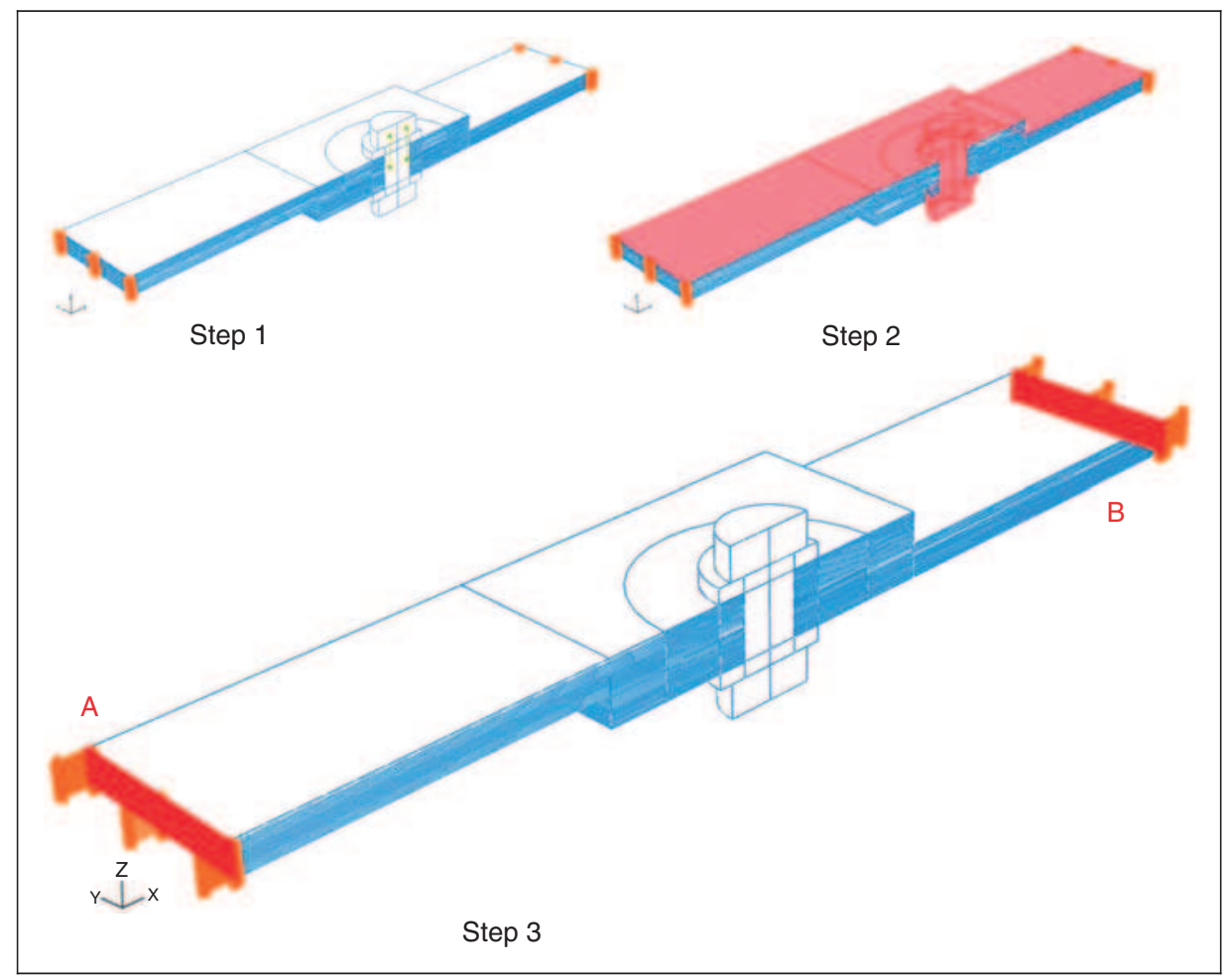

Figure 2. Loading procedure of the model.

values were considered: room temperatures $20^{\circ} \mathrm{C}$ and $50^{\circ} \mathrm{C}$. All possible combinations of fastener torque and temperature values previously cited were modeled (up to 16 cases).

The analysis was performed in three steps. In the first one, the preload in bolt was applied at room temperature. In the second step, the thermal load was applied, increasing or decreasing the temperature of the joint to the prefixed value. Finally, the mechanical load was applied during the third step. Loading procedure is illustrated in Figure 2.

A constant velocity equal to $0.16 \mathrm{~mm} / \mathrm{s}$ was imposed at contours $\mathrm{A}$ and $\mathrm{B}$ during the third step, in order to analyze the evolution of the load as a function of displacement. The displacement of the contour caused a longitudinal tensile load in direction 1 (Figure 1); the step was stopped once the maximum allowed longitudinal load was reached. An experimental work published by Ekh and Schön ${ }^{11}$ was used as a reference, both to define the maximum load preventing the failure of the joint and also for validation of the numerical model presented in this article. This maximum load was stated equal to $3000 \mathrm{~N}$, leading to a safety coefficient equal to 2 , for the joint analyzed in this study.

The scheme of load application corresponds with the current process when the actual joint is considered (torque application at room temperature, followed by thermal loading and subsequent mechanical loading due to structural forces during component service).

\section{Numerical results and discussion}

\section{Load displacement curves}

The load-displacement curves, obtained from all cases simulated are shown in Figure 3. In order to account for the preload originated due to torque and temperature field, both effects are represented at zones A and B, respectively. It is important to note that the axis $x$ has no physical meaning in this zone, it is just the internal calculation time used in simulations to impose first, the torque, and second, the temperature field. The effect of both parameters on the preload is shown with the value of $y$-coordinate at the vertical lines $\mathrm{Y}^{\prime}$ and $\mathrm{Y}$. 


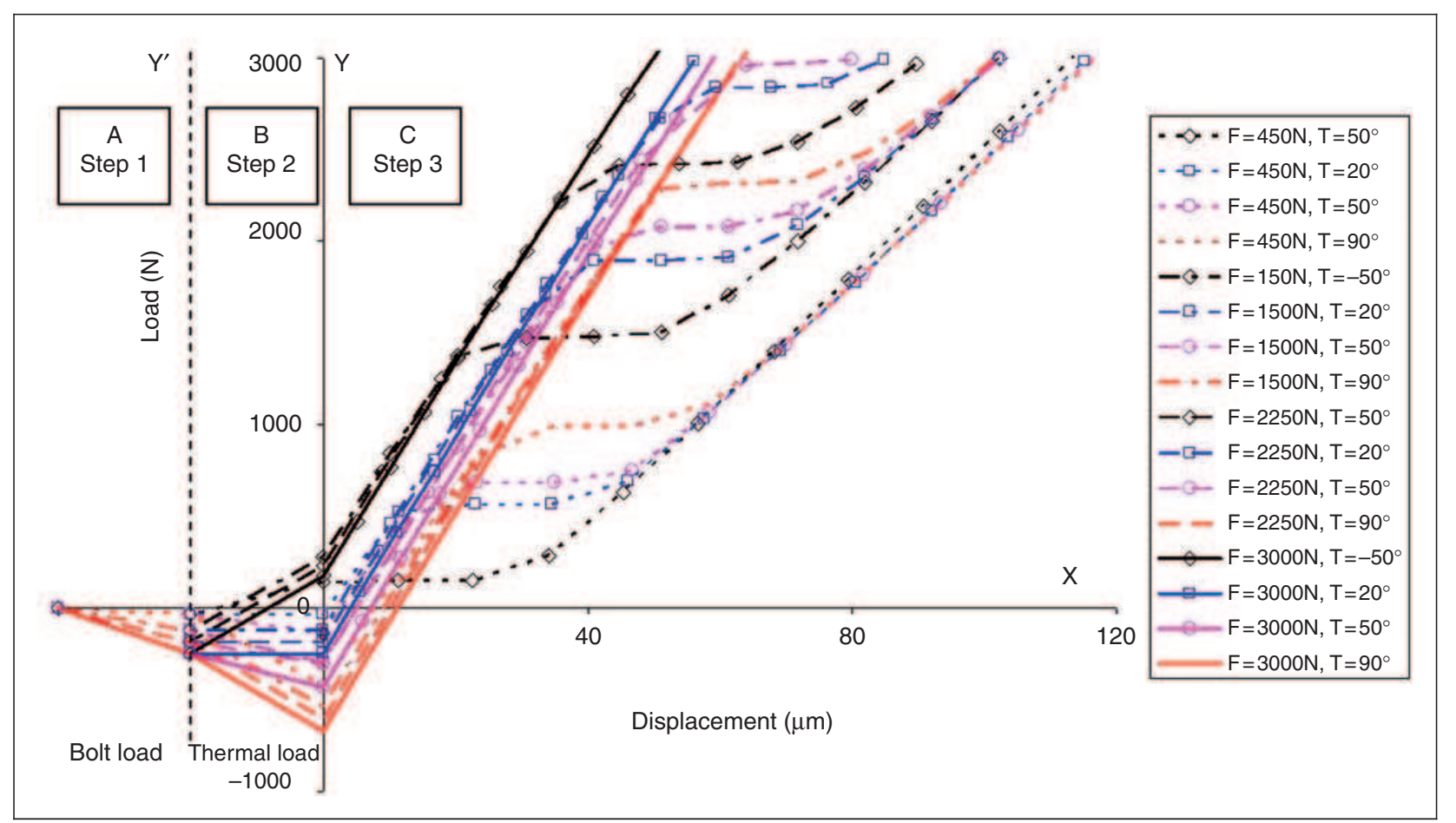

Figure 3. Load-displacement curves for all the cases analyzed.

Zone A corresponds to the first step (the application of torque). Bolt loading led to out-of-plane compressive load on the plates, resulting in a compressive load in direction 1 on the composite plates due to Poisson effect. Although the value of these loads are almost negligible, it is possible to distinguish four different levels of compressive load, acting as a preload which were added to that originated in the following steps.

Zone B shows the effect of thermal load. Variation of temperature led to thermal expansion on the composite and subsequent mechanical loads (tensile in the case of low temperature, compression when high temperature was imposed). These loads were added to those resulting from the first step. Maximum tensile load was achieved with the lowest torque combined with the lowest temperature. Maximum compressive load was associated to the highest torque combined with the maximum temperature.

Zone $\mathrm{C}$ corresponds to step 3; the $x$-axis represents displacement of the contours A and B at constant velocity (Figure 2). Significant influence of torque value and temperature on the load-displacement curve was found. First of all, it should be noted that the friction forces at the interface of washer-plate and plate-plate were strongly influenced by the out-of-plane load produced by the bolt torque and the thermal expansion through the normal load at the interface. The high levels of friction forces were produced by high torque and high temperature due to the enhanced normal force at the interface.

The relative displacement between the bolt and the plates was inversely dependent on the friction forces. The higher values of the friction forces were associated to low displacements, causing the displacement to be lower than the clearance; thus no contact between the bolt and the inner surface of the hole was produced. On the contrary, the lower values of the friction forces led to a relative displacement between bolt and plates higher than the clearance, where the contact force between the bolt and the inner surface is added to the friction force.

When the highest value of torque was considered, no contact between the bolt and the inner surface of the plates occurred; thus linear dependence of the load on the displacement was observed for all temperatures analyzed with the highest torque. Although this behavior could be interpreted as an advantage due to the lower displacement observed in these cases for the maximum design load, the level of stress should be analyzed as shown in the following section. Since the increment of temperature resulted in enhanced compressive load, the total displacement required to reach the maximum tensile load stated as a limit $(3000 \mathrm{~N})$ was also increased.

If the value of torque was equal or lower than that established in ASTM D5961 standard, ${ }^{17}$ the relative displacement between the bolt and the plates was 
higher than the clearance. Thus, the contact between the bolt and the inner surface of the plates produced a contact force added to the friction forces. Consequently, the load-displacement curve shows a break in the linear relationship corresponding to initiation of inner contact. From this point, the displacement was enhanced up to a maximum value increasing with temperature and decreasing with torque.

\section{Stresses and damage indicators}

The safety of the joint was analyzed in terms of the maximum values of stresses. As it is well known, damage indicators are dependent on stress fields, and thus critical values of stresses should be limited to ensure damage absence.

Table 4 summarizes the most significant values of stresses in the bolt (maximum principal stress) and in the laminate (maximum stress in fiber direction, $\sigma_{11}$; and maximum out-of-plane stress, $\sigma_{33}$ ). The values of $\sigma_{33}$ in Table 4 were always compressive due to the nature of stress state induced on the plates. However, the values of $\sigma_{11}$ in Table 4 corresponded to the maximum absolute value of the stress (either tensile or compressive). Tensile stresses were induced by the tensile external load when the displacement remained below the clearance value (all cases except finger tight torque). Maximum absolute value of compressive stress was higher than that of maximum tensile stress when finger tight torque was imposed, since the displacement was larger than the clearance.

Considering standard torque combined with room temperature as a reference case, normalized stress values are shown in Table 4. Negligible influence of both torque and temperature was observed in the stress state of the bolt. However, the composite stress state was much sensitive to changes in these parameters.

Comparing to the reference value, in the case of the highest temperature, maximum fiber direction stress was increased up to $11 \%$ for the standard torque and $33 \%$ for the highest torque. When low operation temperature was considered, maximum fiber direction stress was decreased to $-149 \%$, which is the most unfavorable case of the finger tight torque.

Concerning the maximum out-of-plane stress, increment of $60 \%$ was found for the standard torque combined with the maximum temperature, when comparing with the reference case. For the highest value of torque, increments in normalized stress ranged from $66 \%$ to $119 \%$.

In order to analyze the damage initiation in the composite, Hashin failure criteria was evaluated. The composite failure criteria proposed by Hashin and Rotem ${ }^{22}$ include four failure modes: fiber tensile failure, fiber compressive failure, matrix cracking, and matrix crushing. Since the bolt torque produced compressive normal stresses in the plates, delamination failure criterion was not considered.

Fiber tension $\left(\sigma_{11}>0\right)$ :

$$
d_{f}^{2}=\left(\frac{\sigma_{11}}{X_{t}}\right)^{2}+\left(\frac{\sigma_{12}^{2}+\sigma_{13}^{2}}{S_{L}^{2}}\right)
$$

Fiber compression $\left(\sigma_{11}<0\right)$ :

$$
d_{f}^{2}=\left(\frac{\sigma_{11}}{X_{c}}\right)
$$

\begin{tabular}{|c|c|c|c|c|c|c|c|c|c|c|}
\hline & & & \multicolumn{4}{|c|}{ Maximum stress (MPa) } & \multicolumn{4}{|c|}{ Normalized maximum stress } \\
\hline & & & $A$ & B & $C$ & $D$ & $A$ & B & $C$ & $D$ \\
\hline \multirow[t]{4}{*}{ Maximum principal stress in the bolt } & $T$ & $50^{\circ}$ & 264 & 326 & 382 & 416 & 0.69 & 0.85 & 0.99 & 1.08 \\
\hline & $T$ & $20^{\circ}$ & 267 & 355 & 384 & 456 & 0.70 & 0.92 & 1.00 & 1.19 \\
\hline & $T$ & $50^{\circ}$ & 274 & 368 & 388 & 477 & 0.71 & 0.96 & 1.01 & 1.24 \\
\hline & $T$ & $90^{\circ}$ & 289 & 382 & 396 & 505 & 0.75 & 0.99 & 1.03 & 1.32 \\
\hline \multirow[t]{4}{*}{ Maximum $\sigma_{11}$ in the plates (fiber direction stress) } & $T$ & $50^{\circ}$ & 726 & 465 & 434 & 524 & 1.49 & 0.96 & 0.89 & 1.08 \\
\hline & $T$ & $20^{\circ}$ & 646 & 461 & 486 & 579 & 1.33 & 0.95 & 1.00 & 1.19 \\
\hline & $T$ & $50^{\circ}$ & 624 & 461 & 500 & 608 & 1.28 & 0.95 & 1.03 & 1.25 \\
\hline & $T$ & $90^{\circ}$ & 536 & 465 & 540 & 646 & 1.10 & 0.96 & I.II & 1.33 \\
\hline \multirow[t]{4}{*}{ Maximum $\sigma_{33}$ in the plates (out of plane stress) } & $T$ & $50^{\circ}$ & 58 & 65 & 80 & $14 \mid$ & 0.68 & 0.76 & 0.94 & 1.66 \\
\hline & $T$ & $20^{\circ}$ & 52 & 72 & 85 & 165 & 0.61 & 0.85 & 1.00 & 1.94 \\
\hline & $T$ & $50^{\circ}$ & 52 & 75 & 89 & 175 & 0.61 & 0.88 & 1.05 & 2.06 \\
\hline & $T$ & $90^{\circ}$ & 55 & 77 & 136 & 186 & 0.65 & 0.91 & 1.60 & 2.19 \\
\hline
\end{tabular}

Table 4. Maximum values of stresses and normalized stresses

Bolt preload: $A=450 \mathrm{~N} ; B=1500 \mathrm{~N} ; C=2250 \mathrm{~N}$; and $D=3000 \mathrm{~N}$. The shaded boxes correspond to the standard values (room temperature and standard torque). 
Matrix cracking $\left(\sigma_{22}>0\right)$ :

$$
d_{m t}^{2}=\left(\frac{\sigma_{22}+\sigma_{33}}{Y_{t}}\right)^{2}+\left(\frac{\sigma_{12}^{2}+\sigma_{13}^{2}}{S_{L}}\right)^{2}+\left(\frac{\sigma_{23}^{2}-\sigma_{22} \sigma_{33}}{S_{T}^{2}}\right)^{2}
$$

Matrix crushing $\left(\sigma_{22}<0\right)$ :

$$
\begin{aligned}
d_{m c}^{2}=\frac{1}{Y_{c}} & {\left[\left(\frac{Y_{c}^{2}}{2 S_{T}}\right)^{2}-1\right]\left(\sigma_{22}+\sigma_{33}\right)+\left(\frac{\sigma_{22}+\sigma_{33}}{2 S_{T}}\right)^{2} } \\
& +\frac{\left(\sigma_{23}^{2}+\sigma_{22} \sigma_{33}\right)}{S_{T}^{2}}+\frac{\left(\sigma_{12}^{2}+\sigma_{13}^{2}\right)}{S_{L}^{2}}
\end{aligned}
$$

where $\sigma_{i j}$ denotes the corresponding component of the stress tensor.

Values for Hashin failure criteria for both tensile and compressive stresses corresponding to fiber and matrix were obtained in the laminate. Damage fields are shown in Figure 4 corresponding to standard torque at room temperature. The main failure modes were tensile failure of fiber due to the mechanical load and matrix crushing produced by bolt torque.
Maximum values for fiber failure criterion were located at the zone surrounding the hole while lower values were found at the surfaces subjected to friction forces (plate-washer and plate-plate contact surfaces). On the other hand, the maximum values for matrix crushing were found at the contact surfaces between plates and between plates and washers, due to the compression load applied by the bolt torque. Although matrix crushing criterion values were lower than those associated to fiber failure, the matrix crushing criterion were extended on a wider area.

Failure mode distribution was obtained for all the cases analyzed. Table 5 shows the main failure modes at each combination of torque and temperature considered. The maximum values of the matrix failure criteria were found for matrix crushing, for all cases, due to the stress state produced by the bolt torque. The maximum value for the fiber failure was found in compressive failure criterion for finger tight torque, whereas higher bolt torques resulted in a higher value for tensile failure criterion.

The reference case (standard torque and temperature room) was used to validate the numerical results presented in this study. The maximum value of Hashin

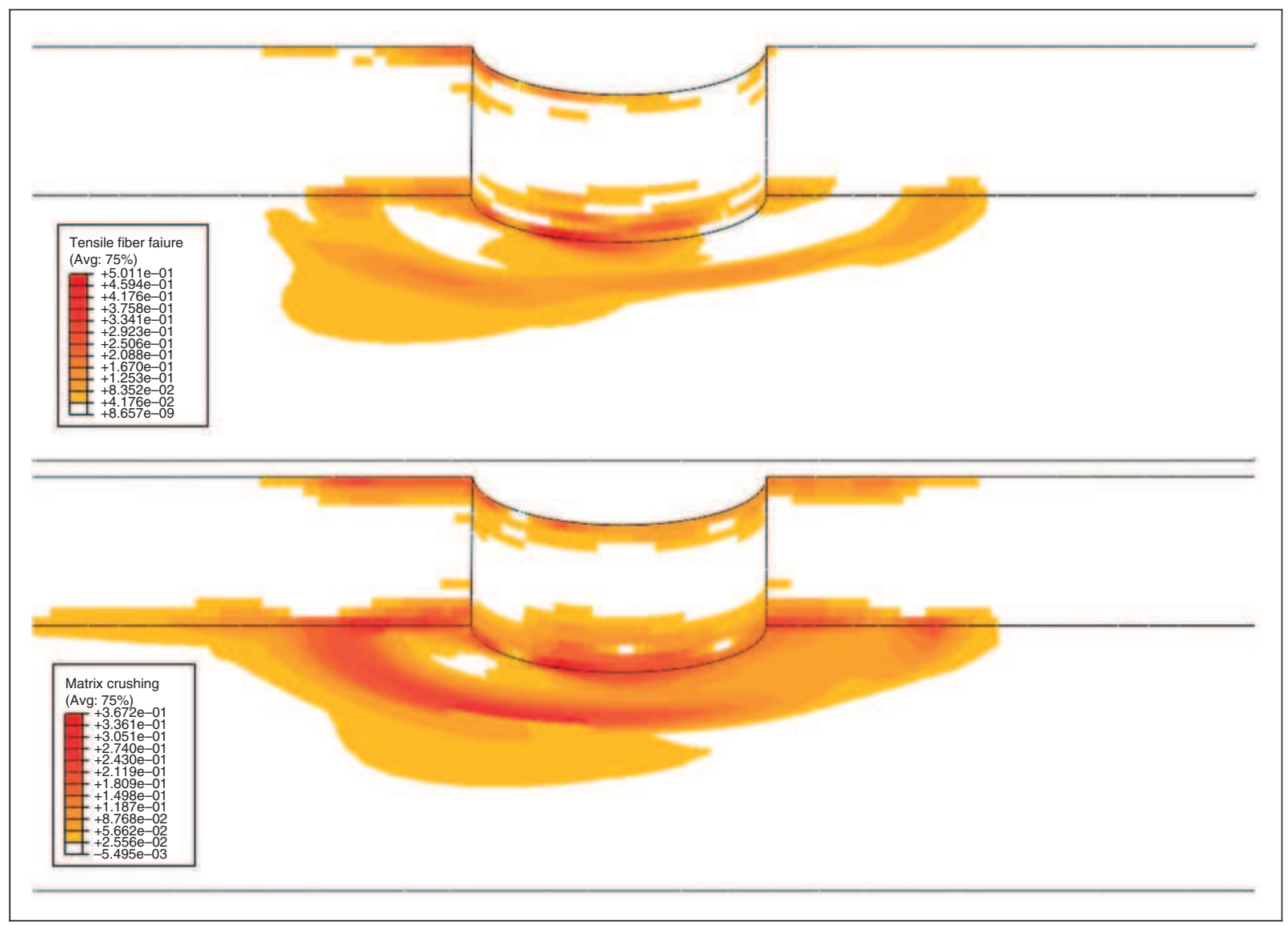

Figure 4. Fields of main failure modes; standard torque and room temperature. 
Table 5. Maximum values of damage indicators

\begin{tabular}{|c|c|c|c|c|c|c|c|c|c|}
\hline & & \multicolumn{4}{|c|}{ Maximum fiber criterion } & \multicolumn{4}{|c|}{ Maximum matrix criterion } \\
\hline & & $A$ & B & $C$ & $D$ & $A$ & B & $C$ & $D$ \\
\hline$T$ & $50^{\circ}$ & 3.26 & 0.44 & 0.46 & 0.64 & 0.52 & 0.27 & 0.50 & 0.64 \\
\hline$T$ & $20^{\circ}$ & 2.37 & 0.41 & 0.50 & 0.68 & 0.28 & 0.23 & 0.37 & 0.67 \\
\hline$T$ & $50^{\circ}$ & 2.16 & 0.40 & 0.59 & 0.71 & 0.24 & 0.26 & 0.57 & 0.86 \\
\hline$T$ & $90^{\circ}$ & 1.39 & 0.41 & 0.71 & 0.75 & 0.10 & 0.40 & 0.75 & 1.15 \\
\hline
\end{tabular}

Torque: $A=450 \mathrm{~N} ; B=1500 \mathrm{~N} ; C=2250 \mathrm{~N}$; and $D=3000 \mathrm{~N}$. The shaded boxes correspond to the standard values (room temperature and standard torque).

criterion which is equal to 0.5 , corresponding to the tensile fiber failure, could be considered as a safety coefficient equal to 2 in agreement with the experimental results obtained in Ekh and Schön. ${ }^{11}$

The use of finger tight torque dramatically increased the criterion values, being representative of damage in the composite. It should be noted that while high values of torque are well recognized to be dangerous for structural integrity of the composite, low values of torque could be even worse for damage initiation. The increase of both temperature and torque with respect to the reference case led to an increased value of this criterion and thus the safety coefficient was diminished. Considering the reference case, an increment of temperature does not produce the failure of the plate, and neither an increment of torque. However the combination of increment of torque and temperature led to a value of matrix crushing criterion equal to 1.15 , showing damage initiation in the matrix.

\section{Conclusions}

Curves of load-displacement relation, stress fields, and damage criterion were obtained with the objective of analyzing the cross-effect of torque and temperature on the joint. Significant influence of the combined parameters was observed.

The standard establishes the recommended fastener torque that should be applied in the bolt to ensure safety of the joint; it was found that critical levels of damage criterion were associated with values of torque below those that recommended by the standard. Moreover, low levels of torque originated larger displacements for the same value of load, when compared with higher values of torque.

On the other hand, high values of torque, above the standard, led to increased values of damage criterion, especially for the matrix, where the failure threshold was reached.

All the values of torque analyzed were influenced by temperature. Although it is a clear factor associated to service life of the component, it has been poorly analyzed in a previous work. Combination of low temperature and low torque was found to be harmful for the fiber. High torque combined with high temperature, resulted in matrix damage values above the limit ensuring joint safety.

Future work will involve the experimental study of the model, just validated in this article with experimental results from literature.

Preliminary results obtained in this article could be of interest when designing the composite joint in order to avoid damage due to the cross-effect of temperature and torque.

\section{Funding}

This work was supported by Spanish Comisión Interministerial de Ciencia y Tecnología [project TRA2004 03960].

\section{References}

1. Xiao $\mathrm{Y}$ and Ishikawa $\mathrm{T}$. Bearing strength and failure behavior of bolted composite joints, part I: experimental investigation. Compos Sci Technol 2005; 65(7 8): 10221031

2. Thoppul SD, Finegan $\mathbf{J}$ and Gibson RF. Mechanics of mechanically fastened joints in polymer matrix composite structures a review. Compos Sci Technol 2005; 69(3 4): 301329.

3. Park H J. Bearing failure analysis of mechanical fastened joints in composite laminates. Compos Struct 2001; 53: 199211.

4. Kelly G and Hallstrom S. Bearing strength of carbon fibre/ epoxy laminates: effects of bolt hole clearance. Composites Part B 2004; 35(4): 331343.

5. McCarthy CT, McCarthy MA, Stanley WF and Lawlor VP. Experiences with modeling friction in composite bolted joints. J Compos Mater 2005; 39(21): 18811908.

6. McCarthy MA, Lawlor VP, Stanley WF and McCarthy CT. Bolt hole clearance effects and strength criteria in single bolt, single lap, composite bolted joints. Compos Sci Technol 2002; 62(10 11): 14151431.

7. Thomas FP and Zhao Y. Torque limit for composites joined with mechanical fastener. In: 46th AIAA/ASME/ ASCE/AHS/ASC Structures, Structural Dynamics and Materials Conference, Austin, Texas, 1821 April 2005, pp. 1821 . 
8. Chutima S and Blackie AP. Effect of pitch distance, row spacing, end distance and bolt diameter on multi fastened composite joints. Composites Part A 1996; 27(2): 105110.

9. Scarponi C, Marini G and Montanari P. The importance of the temperature and lateral pressure on the CFRP joints strength under uniaxial loading. J Reinf Plast Compos 1997; 16(9): 825847.

10. Camanho PP and Matthews FL. A progressive damage model for mechanically fastened joints in composite lam inates. J Compos Mater 1999; 33(24): 22482280.

11. Ekh J and Schön J. Effect of secondary bending on strength prediction of composite, single shear lap joints. Compos Sci Technol 2005; 65(6): 953965.

12. Sánchez Sáez S, Barbero E and Navarro C. Analysis of the dynamic flexural behaviour of composite beams at low temperature. Compos Sci Technol 2007; 67(11 12): 26162632.

13. Sánchez Sáez S, Barbero E and Navarro C. Compressive residual strength at low temperatures of composite lami nates subjected to low velocity impacts. Compos Struct 2007; 85(3): 226232.

14. Hirano N, Takao Y and Wang WX. Effects of tempera ture on the bearing strength of $\mathrm{CF} /$ epoxy pinned joints. J Compos Mater 2007; 41(3): 335351.
15. Turvey GJ and Wang P. Thermal preconditioning study for bolted tension joints in pultruded GRP plate. Compos Struct 2007; 77(4): 509513.

16. Song MH, Kweon JH, Kim SK, et al. An experimental study on the failure of carbon/epoxy single lap riveted joints after thermal exposure. Compos Struct 2008; 86(1 3): 125134.

17. Song MH, Kweon JH, Kim SK, et al. Standard test method for bearing response of polymer matrix composite lami nates. West Conshohocken, PA: ASTM International, 2005.

18. Soden PD, Hinton MJ and Kaddour AS. Lamina prop erties, lay up configurations and loading conditions for a range of fibre reinforced composite laminates. Compos Sci Technol 1998; 58(7): 10111022.

19. Abaqus explicit user's manual. Version 6.5 edition. Hibbitt, Karlson \& Sorensen Inc. HKS, 2005.

20. Ekh $\mathbf{J}$ and Schon $\mathbf{J}$. Load transfer in multirow, single shear, composite to aluminium lap joints. Compos Sci Technol 2006; 66: 875885.

21. Chen WH, Lee SS and Yeh JT. Three dimensional con tact stress analysis of a composite laminate with bolted joint. Compos Struct 1995; 30(3): 287297.

22. Hashin $\mathrm{Z}$ and Rotem A. A fatigue criterion for fiber reinforced materials. J Compos Mater 1973; 7: 448464. 